\title{
Insight \\ Uncertainty in Discount Models and Environmental Accounting
}

\author{
$\underline{\text { Donald Ludwig }}^{1}, \underline{\text { William A. Brock }}^{2}$, and Stephen R. Carpenter ${ }^{2}$
}

\begin{abstract}
Cost-benefit analysis (CBA) is controversial for environmental issues, but is nevertheless employed by many governments and private organizations for making environmental decisions. Controversy centers on the practice of economic discounting in CBA for decisions that have substantial long-term consequences, as do most environmental decisions. Customarily, economic discounting has been calculated at a constant exponential rate, a practice that weights the present heavily in comparison with the future. Recent analyses of economic data show that the assumption of constant exponential discounting should be modified to take into account large uncertainties in long-term discount rates. A proper treatment of this uncertainty requires that we consider returns over a plausible range of assumptions about future discounting rates. When returns are averaged in this way, the schemes with the most severe discounting have a negligible effect on the average after a long period of time has elapsed. This re-examination of economic uncertainty provides support for policies that prevent or mitigate environmental damage. We examine these effects for three examples: a stylized renewable resource, management of a long-lived species (Atlantic Right Whales), and lake eutrophication.
\end{abstract}

Key Words: Atlantic right whale; cost-benefit analysis; discounting; ecological economics; ecosystem service; eutrophication; renewable resource; uncertainty

\section{INTRODUCTION}

Important environmental decisions always involve judgments about incommensurable benefits and costs over long time horizons. Cost-benefit analysis, CBA, is one tool for supporting such decisions (Hanley and Spash 1993, Zerbe and Dively 1994, Daily et al. 2000). In such analyses, costs and benefits of a given policy are computed from the present into the far future, taking into account the expected dynamics of the ecosystem and the economy. Alternative policies can then be ranked according to their net benefit (or cost) over infinite time. Long time horizons are necessary for many environmental decisions. Many environmental changes can be reversed only slowly, and some changes are irreversible (Millennium Ecosystem Assessment 2005). The response of the global climate system to changes in greenhouse gas emissions is delayed for decades to centuries (Nakišenoviš et al. 2000). Lags in recovery of marine and freshwater fisheries are at least on the order of decades for long-lived apex predators (Millennium Ecosystem Assessment 2005). It takes more than a century to reduce phosphorus concentrations of agricultural soils to levels that do not degrade freshwater quality (Bennett et al. 2001, Carpenter 2005). Restoration of damaged ecosystems requires decades to centuries when long-lived species, soil characteristics, or hydrological conditions must be re-established. Many invasive species are extremely difficult to extirpate once they are established, and cause significant losses of native species. Even though local losses of species are reversible in principle, restoration is difficult and the time required for recovery is long. Global extinctions are permanent losses. These are but a few examples illustrating the need for long time horizons when making decisions about ecosystem management (Carpenter 2002).

Wealth measures used in environmental CBA explicitly include changes in natural capital as well 
as in other forms of capital (Dasgupta and Mäler 2000, Daily et al. 2000). Thus CBA can potentially address many dimensions of environmental change, but usually there are practical limitations on the scope of the analysis. When CBA is appropriate and the necessary data and models exist, it yields an index for environmental decision making that complements the information found in other environmental and social indicators (Millenium Ecosystem Assessment 2005). Although environmentalists have sometimes derided economic analysis for measuring "the price of everything and the value of nothing," the results of CBA often favor conservation objectives. For example, the Millennium Ecosystem Assessment (2005) found that the value of undeveloped ecosystems often exceeded the potential value after development, suggesting that properly computed CBAs would often support conservation (rather than conversion) of ecosystems. Market-based conservation mechanisms (such as markets for ecosystem services, ecosystem futures, or certification schemes for sustainably produced goods) are increasing in popularity; e.g., see the Katoomba Group's (

http://www.katoombagroup.org/) Ecosystem Marketplace (

http://www.ecosystemmarketplace.com/). Market mechanisms are a potentially powerful tool for ecosystem management (Millennium Ecosystem Assessment 2005). For example, economic instruments were a key part of the TechnoGarden scenario, which illustrated a number of benefits for conservation and ecosystem services (Millennium Ecosystem Assessment 2005). In addition, governments are increasingly requiring CBAs in support of environmental decisions. These trends suggest that demand for environmental accounting will grow. Proper calculation of CBAs is, therefore, an important issue for ecologists, economists, and the larger community of decision makers.

Environmental CBA is controversial (Leopold 1933, 1934; Bromley 1990; Goulder and Kennedy 1997, Ludwig 2001), and a full review of the controversy is beyond the scope of this paper. We focus instead on a salient point of controversy, the practice of discounting future benefits. Here discounting refers to the process of weighting the sequence of costs or benefits over time. Because long time horizons pervade environmental decisions, uncertainties in projecting future benefits have powerful effects on the outcome of CBA. In particular, the outcome of CBA is extremely sensitive to the choice of discount functions and parameters. If present benefits are weighted too high relative to future ones, ecosystem services may be consumed too fast, degrading natural capital for future generations. Conversely, if present benefits are weighted too low compared with future ones, ecosystem services may be consumed too slowly, robbing the present generation of opportunities. We shall show that the appropriate model for discounting is highly uncertain yet has powerful effects on CBA.

The search for appropriate discounting models is currently an active area of research. The key results are well known in the economic literature (Chichilnisky 1996, Weitzman 1998, Pizer 1999, Heal and Kristom 2002, Frederick et al. 2003, OXERA 2002, Pearce et al. 2003, Newell and Pizer 2003, 2004). However, they have not penetrated the literature of ecosystem management, where their implications are profound, as we shall show. For example, consider implementation of a CBA as a practical attempt to implement the welfare model of Arrow et al. (2004). A key ingredient is the social rate of interest on consumption, which is the social rate of discount on future utility plus the rate of growth of aggregate consumption times a term that depends on the intertemporal elasticity of substitution in consumption (Arrow et al. 2004, pp. 155-156). A proper CBA implementation of a conceptual framework like that of Arrow et al. (2004) requires a proxy not only for the social rate of discount, but also a proxy for the flow of economic value, where both proxies can be constructed from data. This is one way of taking into account the interests of future generations. A different, complementary approach has been advocated by Sumaila and Walters (2005), taking explicit account of the interests of future generations. They point out that the MagnusonStevens Fisheries Conservation and Management Act of the USA mandates that the interests of future generations be taken into account. These ideas have been applied to a detailed model for the Atlantic cod (Gadus morhua) fishery by Ainsworth and Sumaila (2005).

To illustrate the power of discounting assumptions, we present a famous and controversial result due to Colin Clark (1990). Consider a renewable resource subject to harvest, such as a population of fish, wildlife, or trees. Given a model for the population dynamics of the resource, and assuming a simple exponential model for discounting the value of future harvest, one can compute the optimal 
population (or stock size) of the resource (App. 1). This optimal population is the one that maximizes the sum of discounted benefits over infinite time. In Fig. 1, we have plotted the optimal population against the discount rate. The figure shows that it is optimal to harvest the population to extinction if the population growth rate, $r$, is less than or equal to the discount rate. In other words, if money can be invested in a security that grows faster than the population growth rate, then a resource manager should convert all the resource to money and invest in the security. Growth rates of long-lived species such as redwoods, rhinoceroses or whales will often be small compared with interest rates obtainable from alternative investments, say a bank account. This simple CBA suggests that it is optimal to drive such species to extinction. To most people, this result seems obviously wrong. Once the species is extinct, we forever lose all options for benefits from the species, including benefits that are unknown at the present time. Such obvious errors have caused some environmentalists to reject CBA. Modern results in economics show, however, that results such as Fig. 1 are simplistic. Proper accounting for uncertainty in the discount process and such factors as the option value of preserving the species (MacDonald and Seigel 1986), nonconsumptive values, and increasing harvesting costs as the stock is depleted will support lighter harvest of the species.

The purpose of this paper is to explain recent advances in discounting for environmental CBA, and to illustrate their consequences for selected examples of environmental decision making. The general pattern is that proper accounting for uncertainty leads to policies that conserve ecosystems, compared with older methods that neglect uncertainty in the discount process. First, we explain discounting in the context of environmental CBA. Then, we illustrate the effects of different discount models for three ecological examples: (1) a stylized renewable resource, (2) the case of Atlantic right whales, and (3) lake eutrophication, a biogeochemical example of an ecosystem subject to regime shifts. We close with a discussion of the implications of uncertainty for CBA in the context of ecosystem management.

\section{BASICS OF ENVIRONMENTAL COST- BENEFIT ANALYSIS}

The process of computing a CBA for an environmental project or policy is as follows. First, the net benefit generated by the project or policy at each point in time is calculated. This time series of net benefits includes all of the benefits and costs of the project or policy at each point in time, in a common unit (usually currency). The assessment of benefits and costs and corrections for various distortions is a complicated technical exercise (Harberger 1971, Hanley and Spash 1993, Zerbe and Dively 1994). These important issues will not be addressed here. We will assume that a time series of net benefits can be calculated in an appropriate way, in order to focus on uncertainty in the discounting process.

The next step is to determine the discount rate at each point in time. This requires, at a minimum, a model of the interaction of preferences and technology to determine the appropriate market rate of required return on investment, i.e., the discount rate (Arrow et al. 2004, especially pages 155-156, Weitzman 2004). Hence, data-disciplined model uncertainty will play an important role in determining the set of discount rate processes, i.e., observed interest rate processes, that we will consider. This issue will be discussed further below. In practice, the observed interest rate of the economy is corrected (for taxes, inflation, risk, etc.) to estimate the discount rate. The CBA, however, requires future discount rates instead of past discount rates. Future discount rates are projected using various time-series models calibrated on past discount rates. The time series of projected future discount rates is used to compute the discounted sum of net benefits over time from the project or policy. It is important to realize that the projected future discount rate is a random variable. Because the future discount rates are a random variable, the discounted net benefit is a random variable. Therefore, one must compute a mathematical expectation over the uncertainty of future net benefits in order to compute discounted net benefit.

Once the discounted net benefits have been computed properly for all projects or policies under consideration, the projects or policies are ranked according to the size of their discounted net benefit. Many books have been written on the devils in the above details (e.g., Hanley and Spash 1993, Zerbe and Dively 1994), but we have laid out enough 
Fig. 1. Optimal population size vs. discount rate for a renewable resource, where the CBA is computed using simple exponential discounting. Results are shown for three values of the population growth parameter, r. For a given value of r, the optimal population size decreases from the maximum sustainable yield to zero as the discount rate increases up to $\mathrm{r}$. The plot shows the log of equation 12, App. 1, for three values of $r$ with $K=100$.

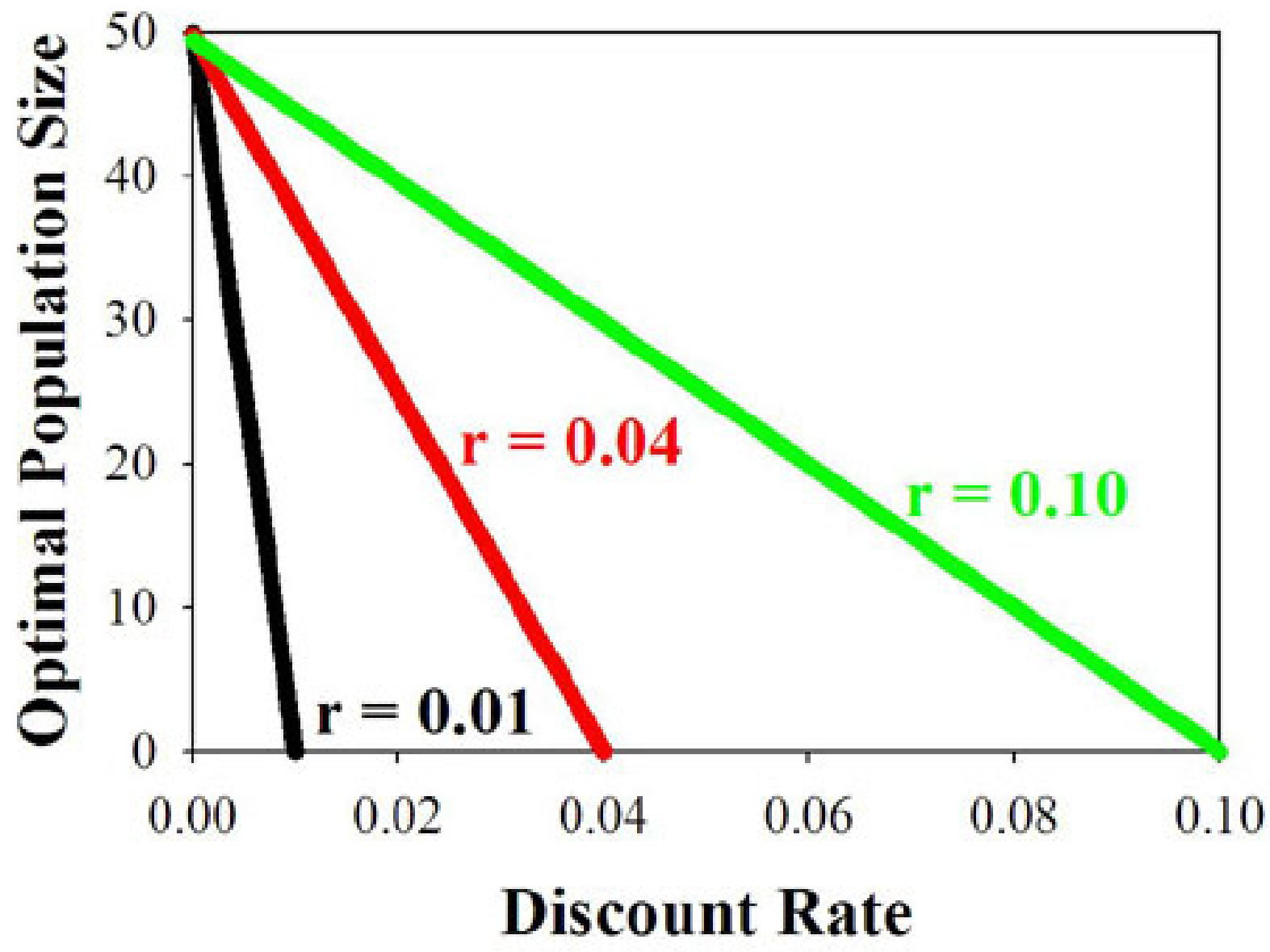

information to exposit the points we wish to make here.

It is clear from the steps above that CBA is a modeling process. In CBA, as in all other areas of science, models are simplifications of reality that are subject to diverse biases and errors. Users of CBA should recognize two profound sources of model uncertainty (Brock et al. 2003, 2005b) for policy evaluation of ecosystem services:

1. The true process that generates future ecosystem services is uncertain and may possess regime shifts or irreversible changes (Scheffer et al. 2001, Carpenter 2003, Folke 
et al. 2005). Models of future ecosystem services are uncertain, and cannot be adequately discriminated by existing data.

2. The true process that generates future discounting rates itself is uncertain, so models of future discount rates are uncertain. Data cannot distinguish among different discount models that have dramatically different consequences for long run valuation in CBA (Groom et al. 2005, Newell and Pizer 2003, 2004).

In order to keep this article brief, we focus on the second source of uncertainty, the economic uncertainty of the discount rates themselves. We consider the impact of this uncertainty for three examples below. In each of the three examples, all other issues mentioned above in application of CBA at each date $t$ are assumed to be solved, in the sense that we assume that we know the ecosystem dynamics and net benefits at each point in time. This simplification allows us to focus on the issue of uncertainty in the discounting process.

\section{THREE EXAMPLES}

Economic equilibrium forces determine future discount rates, but the impact of these forces is notoriously difficult to forecast. A proper accounting for the resulting uncertainty requires that we average returns over a plausible range of assumptions about future discount rates, and that we average over discounting "factors," and not the corresponding "rates": the factors $\mathrm{w}(\mathrm{t})$ and rates $\mathrm{r}$ (t) are related according to equation 1 .

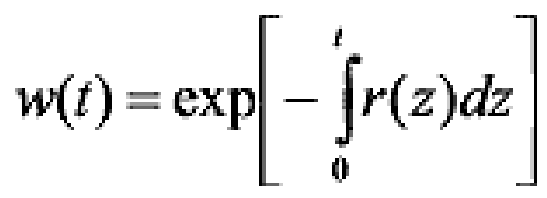

When returns are averaged over discounting factors, the schemes where the discounting is most severe have a negligible effect on the average after a long period has elapsed. To demonstrate this point, consider a simple example in which an environmental project yields \$1 in year 1, and we wish to project the value over 100 years. Suppose we have two simple exponential models for the discount rate, and we infer from historical data that the first model will likely hold $99 \%$ of the time, whereas the second model will hold otherwise (Table 1). Under the first model, which has probability 0.99 , the discount rate is 0.10 . Under the second model, which has probability 0.01 , the discount rate is 0.01 . Table 1 presents $\mathrm{w}$ for $\mathrm{t}=100$ calculated for both models, the probability weighted average, and the value of $r$ corresponding to the probability weighted average. Even though the databased probability is quite small for the low-r model, this model has a large effect on the average discount factor and its corresponding discount rate. This shows that small discount rates have a large effect on the average discount factor, even when the databased support for small discount rates is small. Note that $\mathrm{w}$ is a function of time even if $r$ is not (equation $1)$. The model with the smaller discount rate has an even greater impact on the average discount factor as the time horizon becomes longer. Over longer periods of time, only the lowest discount rate influences the average discount factor.

The key point is that the effective discount rate will decline at approximately the minimum possible discount rate after a long period has elapsed (Weitzman 1998, Pizer 1999, Newell and Pizer 2003, 2004). This has powerful implications for the outcome of CBA, as illustrated by the examples below.

In order to explore the implications of this new approach to discounting, we consider three different models that are obtained from U.S. interest rate data. They are: (i) exponential discounting at a constant discount rate of $4 \%$, (ii) a State Space model, and (iii) Newell and Pizer's (2004) lower possibility for future discount rates. The State Space model is an autoregressive random (time-varying) coefficient model used by Groom et al. (2005) to fit the data. They chose it after applying a series of misspecification tests to simpler models with constant coefficients. It is their best fit for data from the United States. Newell and Pizer have used less sophisticated models to fit the same data. We have chosen their guess for the lowest plausible interest rates in order to illustrate a range of plausible alternatives. Weitzman's gamma discounting model (Weitzman 2001) is based on a questionnaire that asks economists to guess long-term interest rates. It results in rates that are intermediate to those shown. A number of other discount models have 
Table 1. Results of simple example projecting the value of an environmental project over 100 years using two scenarios for the discount rate.

\begin{tabular}{|c|c|c|c|}
\hline Quantity & Scenario 1 & Scenario 2 & $\begin{array}{l}\text { Probability-weighted average of scenarios } 1 \text { and } \\
2\end{array}$ \\
\hline Discount rate $r$ & 0.10 & 0.01 & \\
\hline $\begin{array}{l}\text { Posterior probability calculated from } \\
\text { historical data }\end{array}$ & 0.99 & 0.01 & \\
\hline $\begin{array}{l}\text { Discount factor } \mathrm{w}(\mathrm{t}=100) \text { calculated from } \\
\text { equation } 1\end{array}$ & 0.000045 & 0.37 & $0.99 \times 0.000045+0.01 \times 0.37=0.0037$ \\
\hline Average discount rate & & & $\log [\mathrm{w}(\mathrm{t}=100)] / 100=0.056$ \\
\hline $\begin{array}{l}\text { Projected value of } \$ 1 \\
\exp (\mathrm{r} \times 100)\end{array}$ & $\$ 22026$ & $\$ 2.72$ & $\$ 270.42$ \\
\hline
\end{tabular}

been proposed (Newell and Pizer 2003, 2004, Groom et al. 2005). These alternatives lie in between the models we have chosen. Thus, the models presented here span a range of possibilities published in the economics literature, but we emphasize that the field is still in its infancy: we may expect an even greater variety in the future. The rates for the three discounting models vs. time show that the constant exponential model is the highest of the three (Fig. 2A), whereas the NewellPizer model declines most steeply over time. The state-space model is intermediate.

To illustrate the effects of these discount models on policy choice, we consider three examples of natural resource management: harvest of a renewable resource, protection of Atlantic right whales, and nutrient pollution of a lake subject to eutrophication. Details of all three examples are presented in App. 1.

\section{Example 1: What Population Size is Optimal for a Harvested Resource?}

We first consider harvesting policy for a renewable resource, such as a population of fish, wildlife, or trees. For the case of simple exponential discounting, this problem has been studied by diverse authors for many different populations.

In order to keep the number of parameters in the model to a minimum, we assume that, at each time step, the net value is equal to the number of organisms harvested. The optimal policy consists in seeking to reach a target population size, which depends on the elapsed time and the discounting model. Figure $2 \mathrm{~B}$ shows these targets for the three discounting models. All the discounting strategies are similar for the first few years, but the strategies diverge later as the weightings of future harvests differ more substantially. Under the constant exponential model, optimal management holds the population at $10 \%$ of carrying capacity for all time. Under the Newell-Pizer discount model, the optimal population rises gradually to about $40 \%$ of carrying capacity. For the State Space model, optimal population sizes are intermediate. If economic data indicated that each discount model was equally likely to represent the true discounting process, then the average policy over all models would approach the Newell-Pizer result over time.

A comparison of Figs. 2A and 2B shows that the target population sizes vary inversely with the corresponding discount rates. This illustrates the sensitivity of CBA to discount rates. Reasons for the inverse relationship are explained in App. 1.

Lack of time consistency in the resulting policy might be an objection to the use of declining discount rates: decision makers at a later time $\tau$ may choose to begin the evaluation process anew, and hence may use weights that apply starting from $t=$ $\tau$ rather than $t=0$. Time consistency is an issue for this example, because the more conservative policies (Fig. 2B, black dash, solid green) show a 
Fig. 2. (A) Discount rates vs. time according to three assumptions about future rates: constant rate of $4 \%$ (red dash-dot), State Space (black dash) and Newell and Pizer's lower possibility (green solid). (B) Optimal population size as a function of time in the renewable resource example. (C) Human-caused mortality (proportion of population size) as a function of initial stock size, for optimal management of a hypothetical population of Atlantic right whales. (D) Phosphorus loading rate vs. initial phosphorus mass in the water of a lake, for optimal management of a lake subject to eutrophication if the phosphorus level passes a threshold (normalized to $\mathrm{P}=1$ ).
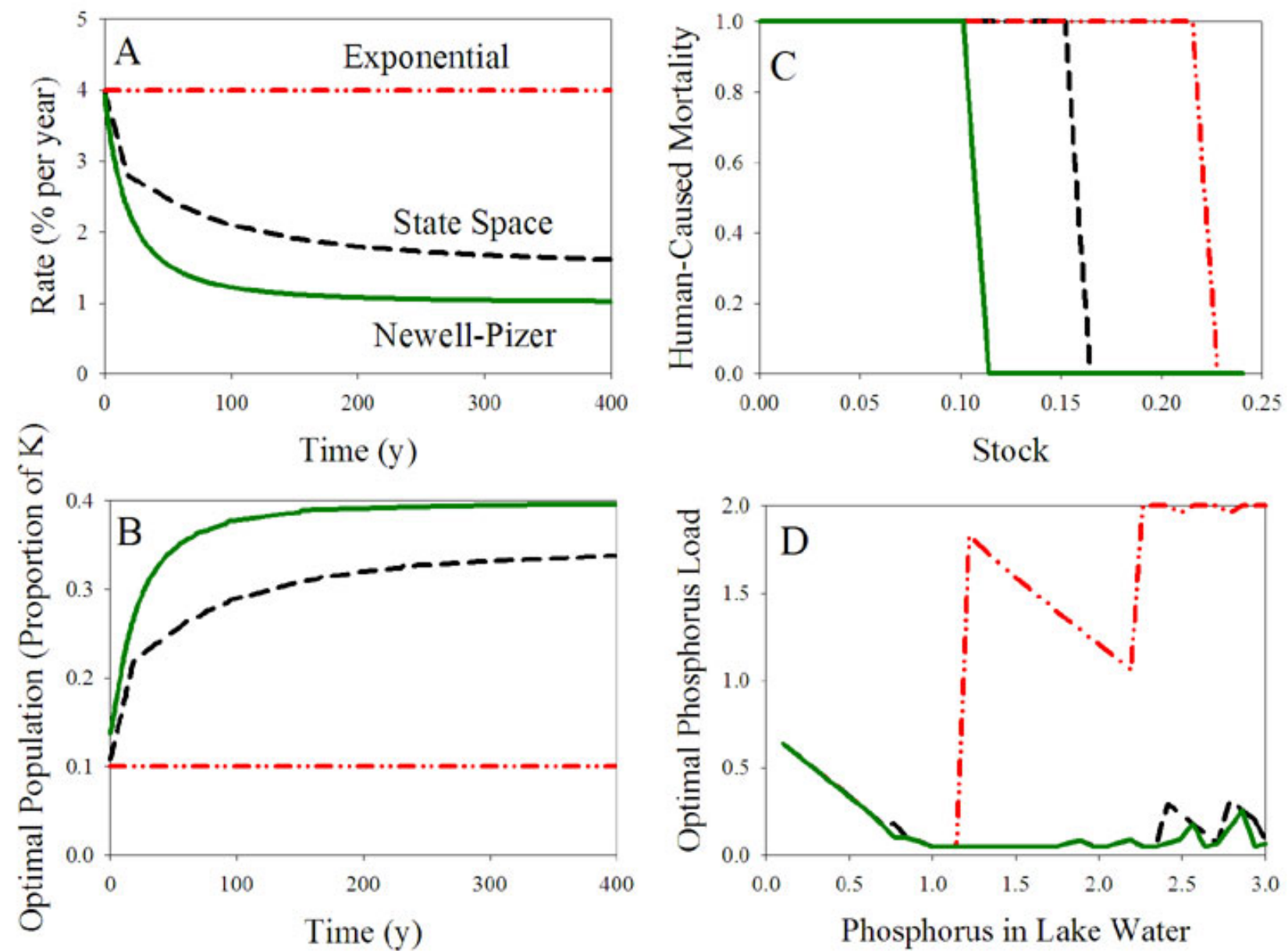

rapid increase in stock targets in early years. Later, decision makers might choose to begin anew, and harvest to low levels. We address this point in the Discussion. Time consistency is not an issue for the next two examples.

\section{Example 2: Should North Atlantic Right Whales be Protected?}

North Atlantic right whales (Eubalaena glacialis) suffer substantial mortality from collisions with ships and entanglement in fishing gear (Kraus et al. 2005). Whales are slow to reproduce, and many 
years are required for a whale population to recover once severely depleted. Tourism and other existence benefits arising from a rehabilitated stock may be uncertain and slow to increase.

However, the costs of diverting ships from their normal routes and changing commercial fishing practices are immediate and continuing. Under what conditions is it worthwhile to divert ships and change fishing practices to protect North Atlantic right whales?

Our calculations show that the optimal economic strategy in such a case is simple: either (a) protect completely against mortality from ship collisions and fishing until the population has recovered, and thereafter protect at a level that maintains an optimal stock size, or (b) provide no protection, and hence eliminate the population as quickly as possible. The choice between these alternatives depends on the time period required to rehabilitate the whale population, and hence it is determined by the current size of the population. This policy is qualitatively similar to many such resource problems. There is an optimal stock size, and the optimal policy seeks to reach that size as quickly as possible, and thereafter maintain it there.

Figure $2 \mathrm{C}$ shows how this choice changes with the discounting model, as a function of size of the whale population. Under constant exponential discounting, the whales should be preserved if their population is more than $23 \%$ of carrying capacity, and allowed to go extinct if the population is lower than $23 \%$ of carrying capacity. For the Newell-Pizer model, the threshold is $11 \%$; the whales should be preserved if the population is above $11 \%$ of carrying capacity, and allowed to go extinct if it is lower than $11 \%$ of carrying capacity. The State Space model is intermediate. If economic data indicated that each discount model was equally likely to represent the true discounting process, then the average threshold over all models would approach the Newell-Pizer threshold of $11 \%$.

Time consistency is not an issue for whale protection. A stock will increase in size once it is being rehabilitated, and so it will qualify for future preservation. Once a stock has been eliminated, future decision makers will have no option to reverse that action. The value of the option to preserve can be quite substantial even if one fails to adjust for uncertainty in the discounting process (McDonald and Siegel 1986).
Although this example shows that correct consideration of discount uncertainty will strengthen the case for preserving North Atlantic right whales, it also highlights the controversial nature of environmental CBA. Many people believe that consigning the North Atlantic right whale to extinction is unethical, regardless of the economic threshold for preservation. We respect this point of view, and do not advocate that CBA should be the sole basis for environmental decision making. We do point out that proper consideration of discount uncertainty broadens the case for species preservation, and in many cases will harmonize economic results with ethical beliefs.

\section{Example 3: How Much Phosphorus Should be Discharged to a Lake?}

Our third example concerns possible eutrophication of a lake due to excessive phosphorus $(\mathrm{P})$ input from agriculture or sewage discharge (Carpenter et al. 1999, Ludwig et al. 2003). This example is similar to many other situations in which ecosystems are altered by release of a long-lived pollutant. Eutrophication is the degradation of lake water quality by excessive inputs of P (Carpenter 2003). Eutrophic lakes are characterized by blooms of noxious (often toxic) algae, oxygen depletion, fish kills, and foul odors. Economic costs of eutrophication include human health risks, increased costs of water treatment for municipal use, loss of fisheries, and loss of recreational amenities (Postel and Carpenter 1997). These must be balanced against short-term benefits of pollutant discharge from agricultural, industrial, or municipal sources; mitigation of $\mathrm{P}$ discharge has immediate and ongoing costs.

Lake $\mathrm{P}$ dynamics show a threshold (Carpenter 2003). Once the P level in the lake exceeds this threshold, it may take many years to return to low $\mathrm{P}$ levels, or in some cases, the lake will never recover. Economic gains that are tied to short-term $\mathrm{P}$ inputs must be balanced against losses of ecosystem services over the long term. Eutrophication has dynamics similar to those of some models of climate change. In both cases, ongoing emission of a pollutant can push an ecosystem over a threshold to a degraded state (National Research Council 2002, Kleinen et al. 2003, Brock et al. 2005a). 
In this case, we plot the optimal pollutant loading (or input) rate as a function of the current level of pollutant in the lake (Fig. 2D). We have normalized the $\mathrm{P}$ level in the lake so that the threshold lies at $\mathrm{P}$ $=1$.

Below the threshold, all discount models show that $\mathrm{P}$ loading should be moderate, and should decline as the threshold is approached from below (Fig. 2D). Above the threshold, the discount models diverge. The exponential model indicates that it is optimal to pollute the lake at a high rate once the threshold is crossed; the lake is irrecoverable, so there are no long-term benefits of clean water to balance against short-term gains from pollutant loading (Carpenter et al. 1999, Ludwig et al. 2003). The Newell-Pizer and State Space models, however, indicate that $\mathrm{P}$ loadings should be low once the threshold is crossed. These policies will eventually decrease the P levels in the lake and restore water quality. If economic data indicated that each discount model was equally likely to represent the true discounting process, then the average policy over all models would approach the Newell-Pizer policy. Thus, when discount uncertainty is properly considered, the lake is managed to restore water quality in the long term. The wiggles in the curves in Fig. 2D are not significant. They result from numerical difficulties in the optimization calculation because of tiny differences in the value function.

Time consistency is not an issue for this and other threshold phenomena. Strategies of restraint in $\mathrm{P}$ loadings result in decreases in $\mathrm{P}$ levels in the lake. Hence, a policy of low P loadings will continue until the water quality is restored.

\section{DISCUSSION}

\section{Time Consistency}

Time consistency is a substantial issue for some environmental decision analyses (Heal 1998, Kasa 2002). In our example of harvesting a renewable resource, the optimal population size changes over time for some discount models (Fig. 2B). What is to prevent a manager from re-computing the optimal policy each year, and thereby maintaining the population at the low levels characteristic of the first few years?
Economists have developed a number of practices to achieve time consistency in long-range planning. Here, we provide a brief, non-technical discussion of these approaches. Consider a real-estate developer who is a long-term planner, and lays out an optimal plan from the present into the future. This optimal plan involves inclusion of parks and greenspace to enhance the value of the houses built by the developer. After all the initial houses have been sold, the developer re-optimizes and finds an extremely strong incentive to renege on the promises not to build on the green space. How can this developer convince prospective buyers that it will not renege on its promise not to develop that green space after all the initial houses have been sold?

Economists who study this issue (the general "theory of credibility") have proposed ways to mitigate this problem (Strotz 1955, Sargent 1987). For all these "commitment technologies," the goal is to get as close as possible to the full commitment solution (the initial optimal plan). Some methods involve constructing credible binding devices, such as putting up monies in escrow accounts that will be lost if promises are broken. An escrow mechanism might work in the case of the developer.

In the case of ecosystem services, how might a management authority, such as a government regulatory agency, be bound to the full commitment solution? There are analogous problems in the economics of inflation management and monetary policy. Devices include institutional insulation of the authority from short-term political pressures, design of employment contracts for the governor of the authority, and the like. In practice, it is important to use monitoring and appropriate ecological indicators to determine if the authority is deviating from its original promises.

Ecological and economic uncertainties about future projections are likely to push the decision maker in the direction of the full commitment solution, if these uncertainties are correctly addressed in the computation of net present value.

Actively adaptive ecosystem management strives to reduce ecological uncertainty by carefully chosen experiments (Walters 1986). If uncertainty is changing rapidly, due to learning through actively adaptive management, it may be appropriate to update and re-calculate optimal policies. 
It is important to note that, in our context, optimal policies will always be time consistent in cases where the decision is to preserve the resource or not. An initial decision to preserve the resource (or not to preserve it) will not be reversed, as in the cases of the North Atlantic right whale and lake eutrophication. Many ecosystem management decisions are of this type. In these cases, the timevarying discount models have unambiguous implications.

\section{Implications for Environmental Accounting}

These examples illustrate how decisive the choice of a discounting scheme can be when calculating CBA of long-term policies. A constant discount rate (sometimes 4\%, but often at much higher rates, such as $10 \%$ ) has been used to support claims that it is economically inefficient to do any investment unless it generates a positive net present value at that rate. In 1972, the U.S. Office of Management and Budget (OMB) directed most federal agencies to apply a " $10 \%$ real rate of discount when calculating present values of government programs, and more recently $\mathrm{OMB}$ has directed agencies to use a 7\% real rate" (Zerbe and Dively 1994). We can now recognize that such analyses rest on unsupported assumptions about future discount rates. Corrections must be made for distortions caused by taxes, risk, etc. in a practical CBA, but fundamental uncertainty in processes that determine future discount rates must also be taken into account. We have shown that accounting for uncertainty may have a profound impact on valuation of long-term projects.

In actual applications of CBA, the discount rates projected by each model will be uncertain, and the decision maker will be uncertain which model applies. The case of uncertain projections within a model is handled by calculating a weighted average (where the weights represent the posterior probabilities) over discount factors (not rates; see equation 1). The case of model uncertainty is handled by weighted averaging of discount factors from each model according to the model's posterior probability based on observed time series of discount rates from the economy under study. Brock et al. (2003, 2005b) discuss model averaging in economics, and Carpenter $(2002,2003)$ presents an ecological example. Because discount factors, not rates, are averaged, the effect of discount uncertainty is to shift the optimal policy toward the lowest possible discount rate (Weitzman 1998).

Uncertainties in the ecosystem dynamics are substantial and beyond the scope of this paper. In general, however, ecological uncertainties push decision analyses toward policies that reduce impact, harvest lightly, mitigate pollutant loading, hedge bets, and experiment (cautiously) with alternative management regimes (Walters 1986, Carpenter 2003, Ludwig et al. 2001, 2003). Thus, the typical effect of ecological uncertainties is to move decision making in the same directions as the economic uncertainties.

We do not advocate that CBA be the sole basis for decisions about ecosystem management. In our current state of ignorance about future dynamics of economies and ecosystems, we face situations that are completely ambiguous, in the sense that plausible future trajectories are so widely dispersed as to be useless for identifying optimal decisions. In these situations, the degree of risk tolerance of the decision makers is paramount. However, in cases where meaningful CBAs can be computed, they provide valuable information for environmental decision making, and should be considered along with other types of information. A large proportion of environmental decisions may be resolved by CBA. Judicious use of CBA may resolve these issues, and thereby free up resources for addressing the more profoundly difficult decisions. We view CBA as a tool, not "the" tool, for decision support in ecosystem management. If CBA is used, it is crucial that uncertainties be properly integrated throughout the process.

In conclusion, environmental decisions, such as those about climate change, persistent pollutants, ecosystem services, harvest of wild resources, and biodiversity, have consequences that span many generations (Millennium Ecosystem Assessment 2005). Similarly, actively adaptive ecosystem management decisions have benefits that occur far in the future (Walters 1997). These long-range decisions are extremely sensitive to assumptions about discounting. At present, there is no single discounting scheme that dominates possible choices. However, schemes with the most severe discounting have a negligible effect on averages after a long period of time has elapsed. This finding provides support for policies that maintain ecosystem services over long time horizons, and prevent or mitigate environmental damage in the present. Analysis of uncertainty is a key element of 
environmental assessments. It is clear that we must scrutinize the choice of discounting scheme as carefully as any other modeling assumption.

Responses to this article can be read online at: http://www.ecologyandsociety.org/vollo/iss2/art13/responses/

\section{Acknowledgments:}

We thank Daniel Schindler and Paul Wade for helpful suggestions. Elena Bennett, Reinette Biggs, Steven Durlauf, and Matt Van de Bogert and two anonymous referees provided helpful reviews of the manuscript. This research was supported by NSERC grants to DL, NSF grants to WAB and SRC, and a McDonnell Foundation grant to the Resilience Alliance.

\section{LITERATURE CITED}

Ainsworth, C. H., and U. R. Sumaila. 2005. Intergenerational valuation of fisheries resources can justify long-term conservation: a case study in Atlantic cod (Gadus morhua). Canadian Journal of Fisheries and Aquatic Sciences 62: 1104-1110.

Arrow, K., P. Dasgupta, L. Goulder, G. Daily, P. Ehrlich, G. Heal, S. Levin, K. G. Maler, S. Schneider, D. Starrett, and B. Walker. 2004. Are we consuming too much? Journal of Economic Perspectives 18(3):147-172.

Bennett, E. M., S. R. Carpenter, and N. F. Caraco. 2001. Human impact on erodable phosphorus and eutrophication: a global perspective. BioScience 51:227-234.

Bradford, D. 1975. Constraints on government investment opportunities and the choice of discount rate. American Economic Review 65:887-899.

Brock, W. A., S. R. Carpenter, and M. Scheffer. 2005a. Regime shifts, environmental signals, uncertainty and policy choice. In J. Norberg and G. Cumming, editors. A theoretical framework for analyzing social-ecological systems. Columbia University Press, New York, New York, USA. In press.

Brock, W., S. Durlauf, and K. West. 2003. Policy evaluation in uncertain economic environments. Brookings Papers on Economic Activity 1:235-301.

Brock, W., S. Durlauf, and K. West. 2005b. Model uncertainty and policy evaluation: some theory and empirics. Working paper. University of Wisconsin, Madison, Wisconsin, USA. (Online.) URL:

http://www.ssc.wisc.edu/econ/archive/wp2004-19. pdf.

Bromley, D. 1990. The ideology of efficiency: searching for a theory of policy analysis. Journal of Environmental Economics and Management 19:86107.

Carpenter, S. R. 2002. Ecological futures: building an ecology of the long now. Ecology 83:2069-2083.

Carpenter, S. R. 2003. Regime shifts in lake ecosystems: pattern and variation. Volume 15, Excellence in Ecology Series, Ecology Institute, Oldendorf/Luhe, Germany.

Carpenter, S. R. 2005. Eutrophication of aquatic ecosystems: bistability and soil phosphorus. Proceedings of the National Academy of Sciences 102:10002-10005.

Carpenter, S. R., D. Ludwig and W. A. Brock. 1999. Management of eutrophication for lakes subject to potentially irreversible change. Ecological Applications 9:751-771.

Chichilnisky, G. 1996. An axiomatic approach to sustainable development. Social Choice and Welfare 13:219-248.

Clark, C. 1990. Mathematical bioeconomics: the optimal management of renewable resources. John Wiley, New York, New York, USA.

Daily, G. C., T. Söderqvist, S. Aniyar, K. Arrow, P. Dasgupta, P. R. Ehrlich, C. Folke, A. M. Jansson, B.-O. Jansson, N. Kautsky, S. Levin, J. Lubchenco, K.-G. Mäler, D. Simpson, D. Starrett, D. Tilman, and B. Walker 2000. The value of nature and the nature of value. Science 289:395-396. (Online.) URL:

http://www.sciencemag.org/cgi/content/ summary/289/5478/395. 
Dasgupta, P., and K. G. Mäler. 2000. Net national product, wealth, and social well-being. Environment and Development Economics 5:69-93.

Folke, C., S. Carpenter, B. Walker, M. Scheffer, T. Elmqvist, L. Gunderson, and C. S. Holling. 2005. Regime shifts, resilience and biodiversity in ecosystem management. Annual Review of Ecology Evolution and Systematics 35:557-581.

Frederick, S., G. Loewenstein, and T. O'Donoghue. 2003. Time discounting and time preference: a critical review. Journal of Economic Literature 40:351-401

Goulder, L. H., and D. Kennedy. 1997. Valuing ecosystem services: philosophical bases and empirical methods. Pages 23-48 in G. Daily, editor. Nature's services. Island Press, Washington, D.C., USA.

Groom, B., P. Koundouri, E. Panopoulou, and T. Pantelidis. 2005. Model selection in the estimation of certainty equivalent discount rates. UCL discussion paper 04/02. Journal of Applied Econometrics: submitted.

Hanley, N., and C. L. Spash. 1993. Cost-benefit analysis and the environment. Edward Elgar, Cornwall, UK.

Harberger, A. C. 1971. Three basic postulates for applied welfare economics: an interpretive essay. Journal of Economic Literature 9:785-797.

Heal, G. 1998. Valuing the future. Columbia University Press, New York, New York, USA.

Heal, G., and B. Kristom. 2002. Uncertainty and climate change. Environmental and Resource Economics 22:3-39.

Kasa, K. 2002. Model uncertainty, robust policies and the value of commitment. Macroeconomic Dynamics 6:145-166.

Kleinen, T., H. Held, and G. Petschel-Held. 2003. The potential role of spectral properties in detecting thresholds in the earth system: application to the thermohaline circulation. Ocean Dynamics 53:5363.

Kraus, S. D., M. W. Brown, H. Caswell, C. W. Clark, M. Fujiwara, P. K. Hamilton, R. D.
Kenney, A. R. Knowlton, S. Landry, C. A. Mayo, W. A. McLellan, M. J. Moore, D. P. Nowacek, D. A. Pabst, A. J. Read and R. M. Rolland. 2005. North Atlantic right whales in crisis. Science 309:561-562.

Leopold, A. 1933. The conservation ethic. Journal of Forestry 31:634-643.

Leopold, A. 1934. Conservation economics. Journal of Forestry 32:537-544.

Ludwig, D. 2001. The era of management is over. Ecosystems 4:758-764.

Ludwig, D., M. Mangel, and B. Haddad. 2001. Science, conservation, and public policy. Annual Review of Ecology and Systematics 32:481-517.

Ludwig, D., S. Carpenter, and W. Brock. 2003. Optimal phosphorus loading for a potentially eutrophic lake. Ecological Applications 13:11351152.

McDonald, R., and D. Siegel. 1986. The value of waiting to invest. Quarterly Journal of Economics 101:707-727.

Millennium Ecosystem Assessment. 2005. Ecosystems and human well-being: general synthesis. Island Press, Washington, D.C., USA. (Online.) URL:

http://www.maweb.org/en/Products.Synthesis.aspx

Nakišenoviš, N., and 26 co-authors. 2000. Special report on emissions scenarios. Cambridge University Press, Cambridge, UK.

National Research Council. 2002. Abrupt climate change: inevitable surprises. National Academy Press, Washington, D.C., USA.

Newell, R. G., and W. A. Pizer. 2003. Discounting the distant future: how much do uncertain rates increase valuations? Journal of Environmental Economics and Management 46:52-71.

Newell, R. G., and W. A. Pizer. 2004. Uncertain discount rates in climate policy analysis. Energy Policy 32:519-529

OXERA. 2002. A social time-preference rate for use in long-term discounting. Office of the Deputy 
Prime Minister, Department for Environment, Food and Rural Affairs, and Department for Transport, London, UK.

Pearce, D., B. Groom, C. Hepburn, and P. Koundouri. 2003. Valuing the future. World Economics 4:121-141.

Pizer, W. A. 1999. The optimal choice of climate change policy in the presence of uncertainty. Resource and Energy Economics 21:255-287.

Postel, S., and S. R. Carpenter. 1997. Freshwater ecosystem services. Pages 195-214 in G. Daily, editor. Nature's services. Island Press, Washington, D.C., USA.

Sargent, T. 1987. Macroeconomic theory. Second Edition. Academic Press, New York, New York, USA.

\section{Scheffer, M., S. Carpenter, J. Foley, C. Folke, and} B. Walker. 2001. Catastrophic shifts in ecosystems. Nature 413:591-596.

Strotz, R. 1955. Myopia and inconsistency in dynamic utility maximization. Review of Economic Studies 23:165-180.

Sumaila, U. R., and C. Walters. 2005. Intergenerational discounting: a new intuitive approach. Ecological Economics 52:135-142.

Walters, C. J. 1986. Adaptive management of renewable resources. MacMillan, New York, New York, USA

Walters, C. J. 1997. Challenges in adaptive management of riparian and coastal ecosystems. Conservation Ecology 1(2): 1. (Online.) URL:

http://www.ecologyandsociety.org/vol1/iss2/art1/.

Weitzman, M. L. 1998. Why the far-distant future should be discounted at the lowest possible rate. Journal of Economic Management 36:201-208.

Weitzman, M. L. 2001. Gamma discounting. American Economic Review 91:260-271.

Weitzman, M. L. 2004. Discounting a distant future whose technology is unknown. Department of Economics, Harvard University, Cambridge, Massachussetts, USA.
Zerbe, R. O. Jr., and D. D. Dively. 1994. Benefitcost analysis in theory and practice. Harper Collins, New York, New York, USA. 
Appendix 1. Appendix 1. Details of the examples presented in the text.

\section{Please click here to download file 'appendixl.pdf'.}

